\title{
Work-family Conflict in Japan: How Job and Home Demands Affect Psychological Distress
}

\author{
Akihito SHIMAZU ${ }^{1 *}$, Arnold B. BAKKER ${ }^{2}$, Evangelia DEMEROUTI ${ }^{3}$ and \\ Maria C.W. PEETERS 4 \\ ${ }^{1}$ Department of Mental Health, The University of Tokyo Graduate School of Medicine. 7-3-1 Hongo, \\ Bunkyo-ku, Tokyo 113-0033, Japan \\ ${ }^{2}$ Department of Work and Organizational Psychology, Erasmus University Rotterdam, Institute of Psychology, \\ PO Box 1738, T12-47, 3000 DR Rotterdam, The Netherlands \\ ${ }^{3}$ Department of Industrial Engineering \& Innovation Sciences, Human Performance Management Group, \\ Eindhoven University of Technology, PO Box 513, 5600 MB Eindhoven, The Netherlands \\ ${ }^{4}$ Department of Social and Organizational Psychology, Utrecht University, PO Box 80.140, 3508 TC Utrecht, \\ The Netherlands
}

Received August 21, 2009 and accepted December 25, 2009

\begin{abstract}
The aim of the present study was to examine how job and home demands are related to psychological distress in a sample of Japanese working parents with preschool children $(n=196)$. We expected that job and home demands are partially related to psychological distress through work-to-family conflict (WFC) and family-to-work conflict (FWC), respectively. Structural equation modeling showed that, as expected, home demands were partially related to psychological distress, both directly and indirectly through FWC. In contrast, job demands were only directly related to psychological distress. The differences between the roles of FWC and WFC are discussed using identity theory.
\end{abstract}

Key words: Home demands, Job demands, Psychological distress, Spillover, Structural equation modeling, Work-family conflict

\section{Introduction}

Research on the predictors of employee health has grown considerably over the past two decades. Most research has focused on predictors that are intrinsic to the work environment, including job demands, job resources (e.g., job control, workplace support), effortreward imbalance, and exposure to physical hazards ${ }^{1-4)}$. However, in recent years, working conditions are rapidly changing. For instance, with the advance of technology (e.g., internet and telecommunication), more and more employees are able to work outside the traditional office and outside traditional work hours ${ }^{5}$, leading to blurred boundaries between work and personal life ${ }^{6}$. In addition, with changes in family structures and increasing participation by women in the workforce ${ }^{7)}$, managing

*To whom correspondence should be addressed.

E-mail: ashimazu@m.u-tokyo.ac.jp the boundaries between home and work is becoming more challenging6). These changes have created the potential for interference or conflict to occur between employees' work and nonwork lives ${ }^{8)}$.

The present study among Japanese working parents with preschool children will focus on how job and home demands are related to psychological distress. In doing so, we will examine whether high job and home demands may initiate a process of work-family conflict, which eventually affects psychological health in an unfavorable way. Work-family conflict is defined as "a form of inter-role conflict in which the role pressures from the work and family domains are mutually incompatible in some respect, such that participation in one role makes it difficult to participate in the other"9). This definition of work-family conflict implies a bidirectional relation between work and family life in such a way that work can interfere with family life (i.e., work-to family conflict: WFC) and family life can interfere with 
work (i.e., family-to work conflict: FWC) ${ }^{4)}$.

Ever since the construct of work-family conflict was introduced, a large body of literature has examined its causes and consequences. According to a meta-analytic review of work-family conflict and its antecedents ${ }^{10)}$, WFC and FWC have different causes; work factors like hours spent at work and job stress are more strongly related to WFC, whereas nonwork factors like hours spent at nonwork and family stress are more strongly related to FWC. These findings are consistent with the role scarcity hypothesis ${ }^{11)}$. Accordingly, people possess limited and fixed amounts of resources (e.g., time and energy). Managing multiple roles (of employee and spouse) is problematic as it draws on the same, scarce resources. For instance, high job demands make employees devote more resources (e.g., time, effort) to work, leaving them with fewer resources to devote to their family, which may result in more experiences of interference from their work with their family lives. Similarly, high home demands make employees devote more resources to family, leaving them with fewer resources to devote to their work, which may result in more experiences of interference from their family lives with their work.

Regarding the health outcomes of work-family conflict, previous studies have explored the relations of work-family conflict with psychological health, physical health, and health-related behaviors of employees ${ }^{12-14)}$. For instance, Peeters et al. ${ }^{7)}$ showed that job and home demands initiate WFC and FWC, respectively, which indirectly results in burnout. In addition, Frone ${ }^{4)}$ revealed that both WFC and FWC are independently and positively related to having a clinically significant mood disorder, anxiety disorder, and substance dependence disorder.

Several models or theories might explain the relationship between work-family conflict and health outcomes ${ }^{15)}$. One of these concerns the effort-recovery model ${ }^{16)}$, which posits that the quantity and quality of recovery from the efforts at work (home) plays a crucial role in the development of consequences ${ }^{17)}$. Accordingly, job (home) demands that require too much effort are associated with the building up of negative load effects that spill over to the home (work) domain. As a consequence, it will be more difficult to recover sufficiently from the effort one has put forth into the job (home). In the end, this will increase the possibility that job (home) demands harm psychological and/or physical health.

The other theory that might shed light on the relationship between work-family conflict and health outcomes is identity theory ${ }^{18,19)}$, which posits that: 1 ) people devote considerable time and energy to constructing and maintaining desired identities, and that 2) people are threatened when their self-images are damaged by impediments to self-identifying activities. According to Frone $^{4)}$, WFC (FWC) represents an impediment to successfully meeting family (work)-related demands and responsibilities, thereby undermining a person's ability to construct and maintain a positive family (work)-related self-image (e.g., "I'm a devoted and successful mother or father"; "I' $m$ a devoted and successful employee, manager, or business owner"). Because both work and family roles represent core components of adult identity, impediments to both work- and family-related identity formation and maintenance are likely to be experienced as stressful ${ }^{4)}$.

Taken together, it can be hypothesized that: (see Fig. 1): Hypothesis 1: Job demands are partially related to psychological distress through WFC. In other words, WFC partially mediates the relationship between job demands and psychological distress.

Hypothesis 2: Home demands are partially related to psychological distress through FWC. In other words, FWC partially mediates the relationship between home demands and psychological distress.

Partial mediation was expected in Hypotheses 1 and 2 because: 1) there is accumulating evidence to suggest that job demands have a strong and direct relationship with outcomes such as psychological distress ${ }^{20}$ and 2 ) our study does not include all possible mediators of the processes under study, such as coping strategies.

Although there have been several studies regarding work-family conflict ${ }^{21-24)}$, their primary focus was the direct effects of work-family conflicts on health outcomes $^{22)}$. This means that the process of how job/home demands have an impact on health outcomes through work-family conflict is less often examined. In addition, although many researchers have recommended the assessment of $\mathrm{FWC}^{14,25,26)}$, research has tended to concentrate only on the role of WFC. Indeed, Peeters et $a .^{7)}$ clarified the importance of both WFC and FWC in the relationship between job/home demands and jobrelated distress namely job burnout. However, the roles of WFC/FWC in the relationship between job/home demands and more general psychological distress are still unclear. Therefore, empirical studies to examine both processes (i.e., job demands $\rightarrow$ WFC $\rightarrow$ psychological distress, and home demands $\rightarrow$ FWC $\rightarrow$ psychological distress) in terms of overall psychological health are especially needed. 


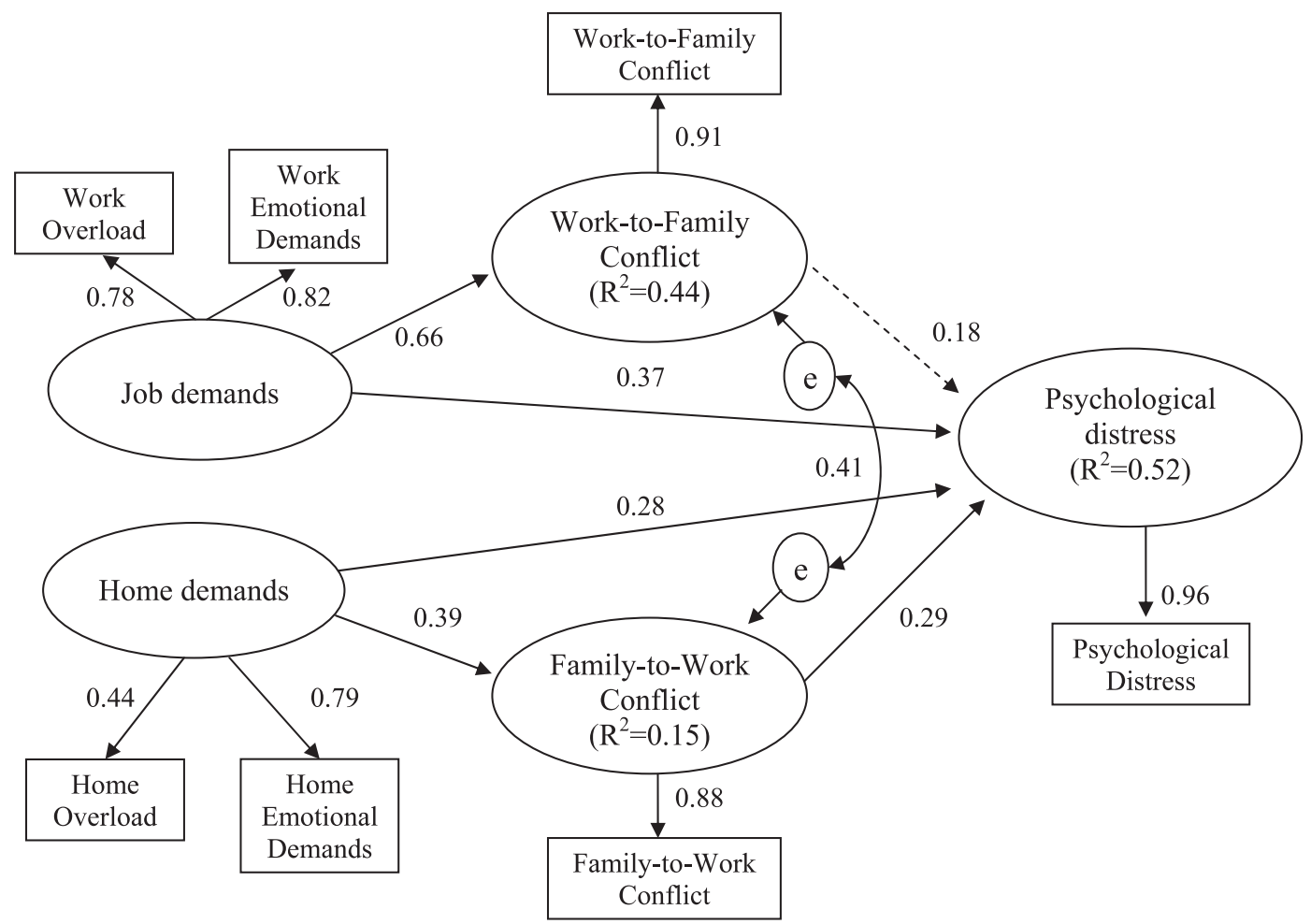

Fig. 1. The hypothesized model (M1) with standardized coefficients ( $=196)$. Dotted line represents non-significant paths $(p>0.05)$.

\section{Methods}

\section{Procedure}

We approached five nursery schools in HigashiHiroshima city, Japan, which were recommended as potential participating organizations by the child-raising assistance department of the city. This procedure ensured that potential respondents belonged to the working population. In a next step, we asked the directors of the nursery schools to participate in our study with an invitation letter. The letter explained the aims, procedures, and ethical consideration of the present study. Four of the five directors agreed to participate.

The data were collected by means of questionnaires. The researchers left two identical questionnaires, one for each partner, in the child's pigeonhole of the nursery schools. Please note that we did not limit potential respondents to dual-earner couples (i.e., we also invited single parents). Participants enrolled in the study on a voluntary basis. The partners were kindly requested to fill out the questionnaires independently. Respondents returned their questionnaires in closed and pre-stamped envelopes to the researcher at the university or through a special box placed in a central position at the entrance of the nursery school. The participants provided information with respect to their levels of job demands, home demands, work-to-family conflict (WFC), family-to-work conflict (FWC), and psychological distress. All the measures were translated from English to Japanese, and then back translated. Ethical approval for the study was obtained from the ethical committee of the university.

\section{Participants}

The participants in the study were 196 working parents with preschool children living in Higashi-Hiroshima city, Japan. Of the 584 questionnaires distributed, 227 were returned, resulting in a response rate of $38.9 \%$. Thirty-one questionnaires could not be used in the analyses due to invalid answers or missing values. As shown in Table 1, the mean age of the participants was $36.7 \mathrm{yr}(\mathrm{SD}=4.7)$ and mean working hours per day was 9.1 $\mathrm{h}(\mathrm{SD}=3.03)$. Of the 196 participants, 95 (48.5\%) were men and 101 women $(51.5 \%) ; 141$ (71.9\%) worked for private companies, $21(10.7 \%)$ were civil servants, 25 $(12.8 \%)$ were self-employed, and the remaining $9(4.6 \%)$ teachers; $153(78.1 \%)$ worked as full-time workers, 37 $(18.9 \%)$ as part-time workers, and the remaining $6(3.0 \%)$ did not give this detail; $78(39.8 \%)$ had one child, 87 $(44.4 \%)$ had two children, $26(13.3 \%)$ had three children, and the remaining $5(2.6 \%)$ had four children. In addition, all participants had at least one child younger than seven years old who lived at home. 
Table 1. Demographic characteristics of participants $(\mathrm{N}=196)$

\begin{tabular}{|c|c|c|c|c|c|}
\hline & & $n$ & Mean & $(S D)$ & $(\%)$ \\
\hline Age & & & 35.6 & $(5.0)$ & \\
\hline Work hours/day & & & 9.1 & $(3.0)$ & \\
\hline \multirow[t]{2}{*}{ Gender } & Men & 95 & & & $(48.5)$ \\
\hline & Women & 101 & & & $(51.5)$ \\
\hline \multirow[t]{4}{*}{ Occupation } & Worker for private company & 141 & & & (71.9) \\
\hline & Civil servant & 21 & & & $(10.7)$ \\
\hline & Self-employed & 25 & & & (12.8) \\
\hline & Others & 9 & & & $(4.6)$ \\
\hline \multirow[t]{3}{*}{ Job contract } & Full-time ( $>=40 \mathrm{~h} / \mathrm{wk}$ ) & 153 & & & (78.1) \\
\hline & Part-time (<40 h/wk) & 37 & & & $(18.9)$ \\
\hline & Missing & 6 & & & (3.0) \\
\hline \multirow[t]{4}{*}{ Number of children } & 1 & 78 & & & $(39.8)$ \\
\hline & 2 & 87 & & & $(44.4)$ \\
\hline & 3 & 26 & & & (13.3) \\
\hline & 4 & 5 & & & (2.6) \\
\hline
\end{tabular}

\section{Measures}

Work overload was measured with four items developed by Furda ${ }^{27)}$ that refer to quantitative, demanding aspects of the job (e.g., time pressure, working hard). These items were validated in previous studies ${ }^{28)}$. Sample items are: "Do you work under time pressure?", and "How often do you have to work extra hard to finish something?" Items are scored on a five-point scale, ranging from (1) 'never' to (5) 'always'. Higher scores indicate higher levels of work overload.

Work emotional demands were assessed with six items developed by Van Veldhoven et $a l^{29}$ ). The scale assesses whether employees have to deal with emotionally charged situations. Example items are: "Is your work emotionally stressful?", and "Does your work involve people who complain continuously or emotionally appeal to you in other way?" (1=never, 5=always). Higher scores indicate higher levels of work emotional demands.

Two home demands developed by Peeters et al. ${ }^{7}$ were included in the questionnaire, namely, home overload and emotional demands. The scales conceptually mirror the job demands scales. Home overload was assessed with five items, including "Do you find that you are busy at home?" Home emotional demands were measured with three items, for example, "How often do emotional issues arise at home?" Responses could be made on a 5-point scale (1=never, 5=always). Higher scores indicate higher levels of home demands.

Work-to-family conflict and family-to-work conflict were assessed with three items each. These items are a selection of the Dutch questionnaire Survey Work-home Interference NijmeGen $(\mathrm{SWING})^{30)}$. Example items are: "How often does it happen that...": "you do not fully enjoy the company of your spouse/family/friends because you worry about your work?" (WFC), "you have difficulty concentrating on your work because you are preoccupied with domestic matters?" (FWC). Responses could be made on a five-point scale ( $1=$ never, $5=$ always). Higher scores indicate higher levels of work-to-family and family-to-work conflicts, respectively.

Psychological distress was measured with a subscale of the Brief Job Stress Questionnaire (BJSQ) ${ }^{31)}$ that includes 15 items, reflecting overall psychological distress (i.e. not limited to work-related distress like burnout); fatigue ("I am completely tired"), anger ("I feel anger"), anxiety ("I feel ill at ease"), and depression ("I feel depressed"). Each item was scored on a fourpoint Likert scale ranging from " $1=$ strongly disagree" to "4=strongly agree". Gotlib and Cane ${ }^{32)}$ showed that it is difficult to discriminate between different types of psychological distress in the workplace. Therefore, we conducted a principal component analysis of the four measures, and only one component with an eigenvalue over one emerged, accounting for $69.3 \%$ of the variance. Furthermore, the alpha coefficients were 0.93, suggesting high internal consistency. Therefore, the four measures were combined into one composite index of psychological distress. Higher scores indicate higher levels of psychological distress.

\section{Data analysis}

To test the hypotheses, we performed a series of structural equation modeling (SEM) analyses, using the AMOS 7.0J software package ${ }^{33)}$. SEM has a number of strengths and has become a very popular data-analytic technique for the clinical and social sciences ${ }^{34)}$. One 
well-known feature is the ability to specify latent variable models that provide separate estimates of relations among latent constructs and their manifest indicators (the measurement model) and of the relations among constructs (the structural model). Another strength is the availability of measures of global fit that can provide a summary evaluation of even complex models that involve a large number of linear equations. In addition, via nested $\chi^{2}$ tests and other means, users can comparatively evaluate the fit of alternative models that differ in complexity. SEM is a theory-driven comprehensive statistical approach for testing theory-based hypotheses.

We analyzed the covariance matrix using the maximum likelihood method of estimation. If $<50 \%$ of the scores of a particular scale was missing, the mean value of the other items of the scale for that individual was computed; otherwise the score of the individual on that scale was regarded as missing. The goodness-of-fit of the models was evaluated using the following absolute goodness-of-fit indices ${ }^{35}$ ): (a) the $\chi^{2}$ goodness-of-fit statistic; (b) the Root Mean Square Error of Approximation (RMSEA); and (c) the Goodness-of-Fit Index (GFI). Since $\chi^{2}$ is sensitive to sample size -i.e., the probability of rejecting a hypothesized model increases with sample size- the use of relative goodness-of-fit measures is strongly recommended ${ }^{36)}$. Therefore, the non-normed fit index (NNFI) was computed as well particularly suitable for comparing models. Since the distribution of the GFI is unknown, no statistical test or critical value is available ${ }^{35)}$. Values smaller than 0.08 for RMSEA are indicative of an acceptable fit, and values greater than 0.1 should lead to model rejection ${ }^{37)}$. For GFI and NNFI, as a rule of thumb, a value greater than 0.90 is considered as indicating a good $\mathrm{fit}^{38)}$.

The theoretical model we tested is presented in Fig. 1. Please note that Fig. 1 also shows the results of analysis. Because of the large number of items, it was not possible to conduct SEM-analysis on a full disaggregation model. The scales introduced above were used as indicators of the latent factors. Job and home demands had two indicators, whereas WFC, FWC, and psycho- logical distress had only one indicator (i.e., the average scores of the scale items). To control for random measurement error for those factors, the error variances of WFC, FWC, or psychological distress was set equal to the product of its variance and one minus the internal consistency ${ }^{35}$ ). We included correlations (correlated error terms) between WFC and FWC, because workfamily conflict is increasingly recognized as consisting of two distinct, though related, concepts ${ }^{10,39)}$.

Using alternative models ${ }^{40)}$, we compared the hypothesized model (including the direct and indirect paths from job/home demands to psychological distress through WFC/FWC, i.e., the partial mediation model) with a model in which the path from job/home demands to WFC/FWC was eliminated (the direct effect model). Moreover, the partial mediation model was compared with the full mediation model, in which the direct path from job/home demands to psychological distress was eliminated. The Sobel $z$ test was used to examine the significance of the mediating effects.

\section{Results}

\section{Descriptive statistics}

The means, standard deviations, internal consistencies (Cronbach's alpha), and correlations between the study variables are displayed in Table 2. As can be seen, all variables have satisfactory reliabilities with Cronbach's alpha coefficients of 0.78 or higher.

\section{Test of the hypothesized model}

Figure 1 shows the results of the hypothesized model (M1). As can be seen in Table 3, all fit indices of the hypothesized model (M1) have values higher than 0.90 and the RMSEA has a value equal to 0.08 . Job demands (i.e. work overload and work emotional demands) are positively related to WFC $(\beta=0.66$, $p<0.001$ ), and home demands (i.e., home overload and home emotional demands) are positively related to FWC $(\beta=0.39, p<0.01)$. Although paths from WFC to psychological distress and from FWC to psychological dis-

Table 2. Range, Means, SDs, Cronbach's Alphas, and Correlations of the variables used in the study (N=196)

\begin{tabular}{lllllllllll}
\hline \multicolumn{1}{c}{ Measures } & Range & Mean & SD & Alpha & 1 & 2 & 3 & 4 & 5 & 6 \\
\hline 1 Work overload & $4-20$ & 13.2 & 4.6 & 0.91 & & & & & & \\
2 Work emotional demands & $6-30$ & 14.2 & 6.0 & 0.90 & $0.63^{* * *}$ & & & & & \\
3 Home overload & $5-25$ & 16.1 & 4.6 & 0.82 & 0.04 & -0.03 & & & & \\
4 Home emotioanal demands & $3-15$ & 7.2 & 2.4 & 0.82 & -0.07 & 0.00 & $0.35^{* * *}$ & & & \\
5 Work-to-family conflict & $3-15$ & 6.4 & 2.9 & 0.84 & $0.50^{* * *}$ & $0.51^{* * *}$ & 0.02 & 0.11 & & \\
6 Family-to-work conflict & $3-15$ & 4.6 & 2.0 & 0.78 & 0.03 & $0.18^{*}$ & $0.20^{* *}$ & $0.29^{* * *}$ & $0.32^{* * *}$ & \\
7 Psychological distress & $15-60$ & 29.9 & 9.3 & 0.93 & $0.32^{* * *}$ & $0.46^{* * *}$ & $0.15^{*}$ & $0.33^{* * *}$ & $0.50^{* * *}$ & $0.44^{* * *}$ \\
\hline
\end{tabular}

$* p<0.05, * * p<0.01, * * * p<0.001$. 
Table 3. Goodness-of-fit indices and $\chi^{2}$ difference tests of nested structural models ( $\left.N=196\right)$

\begin{tabular}{lcccccccccc}
\hline Model & GFI & NNFI & RMSEA & $\chi^{2}$ & df & $p$ & $\begin{array}{c}\text { Model } \\
\text { comparison }\end{array}$ & $\Delta$ df & $\Delta \chi^{2}$ \\
\hline (M1) Hypothesized model & 0.97 & 0.92 & 0.08 & 23.90 & 10 & 0.000 & & & \\
(M2) Direct effects model for job demands & 0.90 & 0.57 & 0.19 & 89.54 & 11 & 0.000 & M1 vs. M2 & 1 & $65.64 * * *$ \\
(M3) Direct effects model for home demands & 0.95 & 0.84 & 0.12 & 39.39 & 11 & 0.000 & M1 vs. M3 & 1 & $15.49^{* * *}$ \\
(M4) Ful mediation model for job demands & 0.95 & 0.87 & 0.11 & 34.54 & 11 & 0.000 & M1 vs. M4 & 1 & $10.64^{* *}$ \\
(M5) Full mediation model for home demands & 0.95 & 0.87 & 0.10 & 34.04 & 11 & 0.000 & M1 vs. M5 & 1 & $10.13^{* *}$ \\
\hline
\end{tabular}

$* * p<0.01, * * * p<0.001$.

GFI = Goodness-of-Fit Index $;$ NNFI $=$ Non-Normed Fit Index $;$ RMSEA $=$ Root Mean Square Error of Approximation.

tress were both positive, the former one was not significant $(\beta=0.18, p=0.12$ and $\beta=0.29, p<0.01$, respectively). Direct paths from job demands to psychological distress and from home demands to psychological distress were both positive and significant $(\beta=0.37, p<0.001$ and $\beta=0.28, p<0.05$, respectively).

In a next step, we conducted an additional analysis to control for demographic variables (i.e., age, gender, occupation, and job contract) as potential confounders. Each control variable was included in the model as a manifest variable simultaneously and allowed to have effects on all model variables. After controlling for confounding variables, the path coefficients were virtually the same as those of hypothesized model (M1), but the model fit worsened $\left(\chi^{2}(10)=34.59, \mathrm{GFI}=0.97\right.$, AGFI $=0.80, \mathrm{NNF}=0.72, \mathrm{CFI}=0.95, \mathrm{RMSEA}=0.11$, $\mathrm{AIC}=146.59$ ). In addition, the relations of control variables to the model variables were weak (i.e. 23 out of 28 paths were not significant, $p>0.05$ ). Hence, we decided not to adopt the model controlling for demographic variables in further analyses.

\section{Formal tests of mediation}

In a final step, we examined the mediating effect of WFC/FWC in the relationship between job/home demands and psychological distress (Table 3). First, the direct effects model, in which the path from job/ home demands to WFC/FWC was eliminated, was compared to the hypothesized model (M1). When the path from job demands to WFC was eliminated, the fit of this alternative model (i.e. direct effects model for job demands - M2) deteriorated significantly $\left(\Delta \chi^{2}(1)=65.64\right.$, $p<0.001)$. Similarly, when the path from home demands to FWC was eliminated, the fit of this alternative model (i.e., direct effects model for home demands - M3) deteriorated significantly $\left(\Delta \chi^{2}(1)=15.49\right.$, $p<0.001$ ).

Next, the full mediation model, in which the direct path from job/home demands to psychological distress was eliminated, was compared to the hypothesized model (M1). When the direct path from job demands to psychological distress was eliminated, the fit of this alternative model (i.e. full mediation model for job demands - M4) deteriorated significantly $\left(\Delta \chi^{2}(1)=10.64\right.$, $p<0.01)$. Similarly, when the direct path from home demands to psychological distress was eliminated, the fit of this alternative model (i.e., full mediation model for home demands - M5) deteriorated significantly $\left(\Delta \chi^{2}(1)=10.13, p<0.01\right)$.

Finally, result of the Sobel-test in the hypothesized model (M1) showed that the mediating effect of FWC in the relationship between home demands and psychological distress was significant $(z=2.05, p<0.05)$, whereas the mediating effect of WFC in the relationship between job demands and psychological distress was nonsignificant $(z=1.54, p=0.12)$.

These results indicated that Hypothesis 2 (i.e., FWC partially mediates the relationship between home demands and psychological distress) was supported, whereas Hypothesis 1 (i.e., WFC partially mediates the relationship between job demands and psychological distress) was not supported.

\section{Discussion}

The present study among Japanese working parents with preschool children focused on how job and home demands are related to psychological distress. In doing so, we examined whether high job and home demands may initiate a process of work-family conflict, which eventually affects psychological health in an unfavorable way. This study provides an opportunity to extend prior research on work-family conflict and psychological health. Specifically, previous studies regarding workfamily conflict ${ }^{21-24)}$ have primarily focused on the direct effects of work-family conflicts on health outcomes ${ }^{22}$ ) and tended to concentrate on the role of $\mathrm{WFC}^{14,25,26)}$. In addition, the roles of WFC/FWC in the relationship between job/home demands and more general psychological distress have less frequently been examined. In contrast, this study examined both processes (i.e., job demands $\rightarrow$ WFC $\rightarrow$ psychological distress, and home 
demands $\rightarrow$ FWC $\rightarrow$ psychological distress) in terms of overall psychological health.

Consistent with Hypothesis 2, we found empirical support for a partial mediating effect of FWC in the relationship between home demands and psychological distress; whereby home demands are related to psychological distress both directly and indirectly through $\mathrm{FWC}^{4}$, 24). In contrast, contrary to our expectation (Hypothesis 1), we did not find empirical support for a partial mediating effect of WFC in the relationship between job demands and psychological distress; job demands were only directly related to psychological distress (i.e., WFC was not significantly related to psychological distress). Although we predicted that both WFC and FWC would partially mediate the relationship between job and home demands on the one hand and psychological distress on the other hand, WFC did not mediate the relationship between job demands and psychological distress. This finding agrees with the results of a four year follow-up study by Frone et $a l^{41)}$. Specifically, while FWC at time 1 was positively related to depression and physical health four years later, WFC was unrelated to both health indicators. The inconsistency between the effects of WFC and FWC on psychological distress may be explained by identity theory ${ }^{18,19)}$.

According to identity theory ${ }^{18,19)}$, people devote considerable time and energy to constructing and maintaining desired identities, and people feel threatened when their self-images are damaged by impediments to self-identifying activities. Since our participants had to devote long hours to their work to fulfil their workrelated responsibilities (i.e., mean working hours was $9.1 \mathrm{~h}$ per day), they were likely to view FWC more threatening to their identity than WFC. This is because, for them FWC represents an impediment to successfully meeting work-related responsibilities, thereby undermining their abilities to construct and maintain a positive work-related self-image (e.g., "I'm a devoted and successful employee, manager, or business owner" $)^{4)}$. As a consequence, FWC was related to increased psychological distress.

However, we cannot conclude that the relationship between WFC and psychological distress $(\beta=0.18$, $p=0.12$ ) is without meaning, because the present analysis is based on a relatively small sample size, which could have resulted in lack of statistical power. We can also not exclude the possibility that WFC does have an effect on psychological distress in the long term. More specifically, although a short-term effect of WFC on psychological distress was not found, its long-term effect is unknown because we used a crosssectional design. As noted by Gollob and Reichardt ${ }^{42)}$, the magnitude of any relation can vary as a function of the length of the time lag separating the measurement of a cause and the measurement of its putative effect. Therefore, a multi-wave design is needed to capture more fully the developmental aspects of the process of interest ${ }^{43)}$, for example, mediating effects of WFC/FWC in the relationship between job/home demands and psychological distress.

This study has some limitations that need to be considered. First, this study is based on cross-sectional survey data with self-report measures. The cross-sectional design of the study inhibits causal inferences of the investigated relationships. Next to self-report bias due to, for example, negative affect, common method variance might have influenced the findings. For example, without controlling for negative affectivity, the associations of job demands with work-family conflicts and the health of employees may be overestimated. So, the true associations might be weaker than the relationships observed in this study. Although several studies have shown that these influences are not as high as could be expected ${ }^{44-46)}$, our findings should be replicated with objective measures (e.g., actual time at work as an index of job demands) in the future.

The second point concerns potential selection biases (i.e., sampling biases and non-response biases). The directors of nursery schools who participated in our study may have been more interested in work-life balance of children's parents compared to the one who did not participate. Further, there is a possibility that the parents who engaged in long hours for working or childrearing could not find time to respond the questionnaire ${ }^{47)}$. It is also conceivable that parents who had low work-family conflict or enjoyed good health did not participate in this survey because of not feeling the need to do so. The results should be interpreted with some caution, because the impact of such a bias is unclear.

\section{Practical implications}

Our findings suggest that job and home demands have direct relations to psychological distress. So, the starting point is to decrease overload and emotional demands in the workplace and at home. Although stress management programs which focus on the improvement of work environment ${ }^{48)}$ become popular, it is time that organizations try to provide training and support for nonwork-related demands (e.g., parental training, role reorientation for couples, possibilities for working at home, or child care facilities) $)^{7}$. Our findings also revealed an indirect relation of home demands to psychological distress through family-to-work conflict. This suggests that concerning with the adverse impact of family responsibilities on organizational outcomes ${ }^{4}$ ) 
results in increased psychological distress. Thus, family-supportive programs (e.g., child care assistance, alternative work schedules) seem promising strategies.

In conclusion, the present study among Japanese dualearner couples clarified the process how job and home demands are related to psychological distress. Job demands were directly related to psychological distress, whereas home demands were related to it both directly and indirectly through FWC.

\section{References}

1) Bakker AB, Demerouti E (2007) The Job demandsresources model: state of the art. J Manage Psychol 22, 309-28.

2) Karasek R (1979) Job demands, Job decision latitude, and mental strain: implication for job redesign. Admin Sci Quart 24, 285-308.

3) Siegrist J (1996) Adverse health effects of higheffort/low-reward conditions. J Occup Health Psych 1, 27-41.

4) Frone MR (2000) Work-family conflict and employee psychiatric disorders: the national comorbidity survey. J Appl Psychol 85, 888-95.

5) $\mathrm{Ng} \mathrm{TWH}$, Sorensen KL, Feldman DC (2007) Dimensions, antecedents, and consequences of workaholism: a conceptual integration and extension. J Organ Behav 28, 111-36.

6) Jones F, Burke RJ, Westman M (2006) Work-life balance: key issues. In: Work-life balance: a psychological perspective, Jones F, Burke RJ, Westman M (Eds.), 1-9, Psychology Press, East Sussex.

7) Peeters MCW, Montgomery AJ, Bakker AB, Schaufeli WB (2005) Balancing work and home: how job and home demands are related to burnout. Int $\mathrm{J}$ Stress Manage 12, 43-61.

8) Bakker AB, Demerouti E, Dollard M (2008) How job demands influence partners' experience of exhaustion: integrating work-family conflict and crossover theory. J Appl Psychol 93, 901-11.

9) Greenhaus JH, Beutell NJ (1985) Sources of conflict between work and family roles. Acad Manage Rev 10, 76-88.

10) Byron K (2005) A meta-analytic review of workfamily conflict and its antecedents. J Vocat Behav 67, 169-98.

11) Edwards JR, Rothbard NP (2000) Mechanisms linking work and family: clarifying the relationship between work and family constructs. Academy of Management Review 25, 178-99.

12) Allen TD, Herst DEL, Bruck CS, Sutton M (2002) Consequenses associated with work-to-family conflict: a review and agenda for future research. J Occup Health Psych 5, 278-308.

13) Kossek EE, Ozeki C (1998) Work-family conflict, policies, and the job-life satisfaction relationship: a review and directions for organizational behaviorhuman resources research. J Appl Psychol 83, 139-49.

14) Kossek EE, Ozeki C (1999) Bridging the workfamily policy and productivity gap: a literature review. Commun Work Fam 2, 7-32.

15) Geurts SAE, Demerouti E (2003) Work/non-work interface: a review of theories and findings. In: The handbook of work and health psychology, Schabracq MJ, Winnubst JAM, Cooper CL (Eds.), 279-312, Wiley, Chichester.

16) Meijman TF, Mulder G (1998) Psychological aspects of workload. In: Handbook of work and organisational psychology, 2nd Ed., Drenth PJD, Thierry H, de Wolff CJ (Eds.), 5-33, Psychology Press/Erlbaum, Hove.

17) Bakker AB, Geurts S (2004) Toward a dual-process model of work-home interference. Work Occup 31, 345-66.

18) Burke PJ (1991) Identity processes and social stress. Am Sociol Rev 56, 836-49.

19) Schlenker BR (1987) Threats to identity: self-identification and social stress. In: Coping with negative life events: clinical and social psychological perspectives, Synder CR, Ford CE (Eds.), 273-321, Plenum, New York.

20) Stansfeld S, Candy B (2006) Psychosocial work environment and mental health - a meta-analytic review. Scand J Work Environ Health 32, 443-62.

21) Greenhaus JH, Beutell NJ (1985) Sources of conflict between work and family roles. Acad Manage Rev 10, 76-88.

22) Eby LT, Casper WJ, Lockwood A, Bordeaux C, Brinley A (2005) Work and family research in IO/OB: content analysis and review of the literature (1980 2002). J Vocat Behav 66, 124-97.

23) Ford MT, Heinen BA, Langkamer KL (2007) Work and family satisfaction and conflict: a meta-analysis of cross-domain relations. J Appl Psychol 92, 57-80.

24) Edwards JR, Rothbard NP (2000) Mechanisms linking work and family: clarifying the relationship between work and family constructs. Acad Manage Rev 25, 178-99.

25) Frone MR, Russell M, Cooper ML (1992) Antecedents and outcomes of work-family conflict: testing a model of the work-family interface. J Appl Psychol 77, 65-78.

26) Kirchmeyer C, Cohen A (1999) Different strategies for managing the work/non-work interface: a test for unique pathways to work outcomes. Work Stress 13, 59-73.

27) Furda J (1995) Werk, persoon en welzijn: Een toets van het JD-C model [Work, personality, and wellbeing: a test of the JD-C model]. Unpublished doctoral dissertation. Utrecht University, Utrecht (in Dutch).

28) Bakker AB, Demerouti E, Taris TW, Schaufeli WB, Schreurs P (2003) A multi-group analysis of the job demands-resources model in four home care organizations. Int J Stress Manage 10, 16-38. 
29) Van Veldhoven M, De Jonge J, Broersen JPJ, Kompier M, Meijman T (2002) Specific relations between psychosocial job conditions and job-related stress: a three-level analytic approach. Work Stress 16, 207-28.

30) Geurts SA, Taris TW, Kompier MAJ, Dikkers SJE, Van Hooff M, Kinnunen U (2005) Work-home interaction from a work-psychological perspective: development and validation of a new questionnaire, the SWING. Work Stress 19, 319-39.

31) Shimomitsu T, Yokoyama K, Ono Y, Maruta T, Tanigawa T (1998) Development of a novel brief job stress questionnaire. In: Report of the research grant for the prevention of work-related diseases from the Ministry of Labour, Kato S (Ed.), 107-15, Japanese Ministry of Labour, Tokyo (in Japanese).

32) Gotlib IH, Cane DB (1989) Self-report assessment of depression and anxiety. In: Anxiety and depression: distinctive and overlapping features, Kendall PC, Watson D (Eds.), 131-69, Academic Press, San Diego.

33) Arbuckle JL (2006) Amos (Version 7.0) [Computer Program]. SPSS, Chicago.

34) Tomarken AJ, Waller NG (2005) Structural equation modeling: strengths, limitations, and misconceptions. Annu Rev Clin Psychol 1, 31-65.

35) Jöreskog KG, Sörbom D (1993) LISREL 8: User's Reference Guide. Scientific Software International, Chicago.

36) Bentler PM (1990) Comparative fit indexes in structural equation models. Psychol Bull 107, 238-46.

37) Cudeck R, Browne MW (1993) Alternative ways of assessing model fit. In: Testing structural equation models, Bollen KA, Long JS (Eds.), 1-9, Sage, Newbury Park.

38) Hoyle RH (1995) The structural equation modeling approach: basic concepts and fundamental issues. In: Structural equation modeling: concepts, issues, and applications, Hoyle RH (Ed.), 1-15, Sage, Thousand
Oaks.

39) Mesmer-Magnus JR, Viswesvaran C (2005) Convergence between measures of work-to-family and family-towork conflict: a meta-analytic examination. J Vocat Behav 67, 215-32.

40) Lehmann D (2001) Structural Equations Modeling. J Consum Psychol 10, 90-2.

41) Frone MR, Russell M, Cooper ML (1997) Relation of work-family conflict to health outcomes: a fouryear longitudinal study of employed parents. J Occup Organ Psychol 70, 325-35.

42) Gollob HF, Reichardt CS (1987) Taking account of time lags in causal models. Child Dev 58, 80-92.

43) Taris TW, Kompier M (2003) Challenges in longitudinal designs in occupational health psychology. Scand J Work Environ Health 29, 1-4.

44) Edwards JR (2008) To prosper, organizational psychology should ... overcome methodological barriers to progress. J Organ Behav 29, 469-91.

45) Spector PE (2006) Method variance in organizational research: truth or urban legend? Organ Res Methods 9, 221-32.

46) Spector PE, Zapf D, Chen PY, Frese M (2000) Why negative affectivity should not be controlled in job stress research: don't throw out the baby with the bath water. J Organ Behav 21, 79-95.

47) Hill EJ, Hawkins AJ, Ferris M, Weitzman M (2001) Finding an extra day a week: the positive influence of perceived job flexibility on work and family life balance. Fam Relat 50, 49-58.

48) Tsutsumi A, Nagami M, Yoshikawa T, Kogi K, Kawakami N (2009) Participatory intervention for workplace improvements on mental health and job performance among blue-collar workers: a cluster randomized controlled trial. J Occup Environ Med 51, 554-63. 